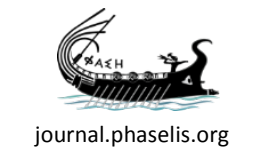

journal.phaselis.org

\title{
Phaselis, Bostanlık Koyu Kumsalı'nda Yuva Yapan Caretta caretta (Linnaeus, 1758) Populasyonlarının 2015 Üreme Sezonunda İzlenmesi
}

\author{
Monitoring Caretta Caretta (Linnaeus, 1758): The Population \\ Nesting at Bostanlık Beach in Phaselis in the 2015 Nesting \\ Season
}

Mustafa YAVUZ - Recep GÜLER

PHASELIS: Disiplinlerarası Akdeniz Araştırmaları Dergisi'nde bulunan içeriklerin tümü kullanıcılara açık, serbestçe/ücretsiz "açık erişimli" bir dergidir. Kullanıcılar, yayıncıdan ve yazar(lar)dan izin almaksızın, dergideki makaleleri tam metin olarak okuyabilir, indirebilir, dağıtabilir, makalelerin çıktısını alabilir ve kaynak göstererek makalelere bağlantı verebilir.

PHASELIS: Disiplinlerarası Akdeniz Araştırmaları Dergisi uluslararası hakemli elektronik (online) bir dergi olup değerlendirme süreci biten makaleler derginin web sitesinde (journal.phaselis.org) yıl boyunca ilgili sayının içinde (Volume II: Ocak-Aralık 2016) yayımlanır. Aralık ayı sonunda ilgili yıla ait sayı tamamlanır.

Dergide yayımlanan eserlerin sorumluluğu yazarlarına aittir.

M. Yavuz - R. Güler, “Phaselis, Bostanlık Koyu Kumsalı'nda Yuva Yapan Caretta caretta (Linnaeus, 1758) Populasyonlarının 2015 Üreme Sezonunda İzlenmesi”. Phaselis II (2016) 155-165. DOI: 10.18367/Pha.16010

Geliş Tarihi: 12.01.2016 | Kabul Tarihi: 06.04.2016 | Elektronik Yayın Tarihi: 01.08.2016 


\title{
Phaselis, Bostanlık Koyu Kumsalı'nda Yuva Yapan Caretta caretta (Linnaeus, 1758) Populasyonlarının 2015 Üreme Sezonunda İzlenmesi
}

\author{
Monitoring Caretta Caretta (Linnaeus, 1758): The Population Nesting at Bostanlık \\ Beach in Phaselis in the 2015 Nesting Season
}

\author{
Mustafa YAVUZ* Recep GÜLER ${ }^{* *}$
}

\begin{abstract}
Öz: Bu çalışmada 2015 yılı üreme döneminde, Phaselis antik kenti kapsamında yer alan Bostanlık Kumsalı'nda yuva yapan iribaşı ıeniz kaplumbağalarının (Caretta caretta) popülasyon durumları araştııılmıştır. Phaselis'in Bostanlık Koyu Kumsalı ortasına yakın kııımdan uzanan kayalık burun nedeniyle Doğu (yaklaşık $350 \mathrm{~m}$ ) ve Batı (yaklaşık $500 \mathrm{~m}$ ) kumsalı olarak iki ayrı bölüme ayrılmışır. Üreme sezonunda yapılan bu ön çalışmada Bostanlık Koyu Kumsalı'nın Batı bölümünde toplam 12 yuva tespit edilmiş, bu yuvalardan 8'inde (\%66.7) yavru çııışı gerçekleşmiştir. Geri kalan 4 yuva ise predatörler tarafından tahrip edilmiştir. Diğer taraftan turistlerin ve halkın yoğun olarak kullandığı Doğu bölümünde ise hiçbir çıkışa rastlanmamıştır.
\end{abstract}

Anahtar Sözcükler: Phaselis · Bostanlık Koyu Kumsalı · Caretta caretta · Antalya

Abstract: In this study, the status of the loggerhead sea turtle (Caretta caretta) nesting in the ancient city of Phaselis at the Bostanlık Bay Beach was investigated. The beach is divided into two sections (eastern section about $350 \mathrm{~m}$ and west approximately $500 \mathrm{~m}$ ) due to the rocky headland dividing the beach. During the breeding season a total of 12 nests was recorded in the western section and 8 (66.7\%) of these nests produced hatchlings. The remaining 4 nests were predated. On the other hand, in the east subsection which is being used extensively by tourists and local peoples no nest was recorded.

Keywords: Phaselis · Bostanlık Bay Beach · Caretta caretta $\cdot$ Antalya

\section{Giriş}

Dünyada bilinen sekiz tür deniz kaplumbağası yaşamaktadır ${ }^{1}$. Bu türler; Caretta caretta (iribaş kaplumbağa), Chelonia mydas (yeşil deniz kaplumbağası), Chelonia agassizzii (siyah deniz kaplumbağası), Dermochelys coriacea (deri sırtlı kaplumbağa), Lepidochelys kempi (gündüz yuvalayan kaplumbağa), Lepidochelys olivacea (zeytin yeşilli kaplumbağa), Eritmochelys imbricata (atmaca gagalı kaplumbağa) ve Natator depressus'tur (düz sırtlı kaplumbağa). Bu türlerden beşinin Akdeniz havzası içerisinde bulundukları bilinmektedir ${ }^{2}$. Bu beş türden Caretta caretta ve Chelonia mydas, Türkiye'nin Akdeniz sahillerine düzenli olarak yuva yapmaktadır ${ }^{3}$. Dermochelys

* Yrd. Doç. Dr., Akdeniz Üniversitesi, Fen Fakültesi, Biyoloji Bölümü, Antalya. myavuz2006@gmail.com

** MA., Akdeniz Üniversitesi, Fen Fakültesi, Biyoloji Bölümü, Antalya. recep.gulr@gmail.com

$1 \quad$ Lutz - Musick 1997.

2 Mrosovsky 1983; 1994; Groombridge 1988.

3 Hathaway 1972; Başoğlu 1973; Geldiay - Koray 1982; Sella 1982; Geldiay 1983; 1984; Groombridge 1988; Baran - Kasparek 1989; Yerli 1990; Groombridge 1990; Baran 1990; Canbolat 1991; Baran et al. 1992; Kaska 
coriacea, Lepidochelys kempii ve Eritmochelys imbricata türleri Akdeniz'de de yaşamaktadır. Fakat bugüne kadar yapılan çalışmalarda bu türlerin Türkiye'nin Akdeniz sahillerinde yuva yaptıklarına dair herhangi bir kayıt bulunmamaktadır ${ }^{4}$.

C. caretta ve $C$. mydas türleri Bern Sözleşmesi (Convention on the Conservation of European Wildlife and Natural Habitats) ve CITES (The Convention of the International Trade in Endangered Species) ile koruma altına alınmıştır. Bu iki tür aynı zamanda IUCN (International Union for Conservation of Nature and Natural Resources) Kırmızı Liste'de (Red List) "endangered" yani "doğada soyu tükenme tehlikesi olan türler" arasındadır".

Bu iki türden, Caretta caretta, Mısır, Libya, Tunus, Yunanistan, Türkiye ve Kıbrıs kıyılarına yuva yaparken diğer tür Chelonia mydas ise yalnızca Türkiye ve Kıbrıs sahillerine yuvalamaktadır ${ }^{6}$. Türkiye'nin Akdeniz sahilleri yuvalama açısından Caretta caretta için Yunanistan ve Libya'dan (eğer yuvalama bilgileri doğruysa) sonra en önemli üçüncü, Chelonia mydas içinse en önemli bölgedir. Bu iki tür sahillerimize yoğun olarak yuva yapmaktadır. Örnek vermek gerekirse; Türkiye'nin Akdeniz kıyılarındaki yıllık deniz kaplumbağası yuva sayısı C. caretta için 1547- 2485 (ort. 2005) ve C. mydas için 391-910 (ort. 647,6) yuvadır?

Bu iki tür gerek korunma durumu açısından gerekse yuvalama alanlarının büyük kısmının ülkemizin Akdeniz sahillerinde olmasından dolayı, Türkiye için oldukça önemlidir. Türkiye'de deniz kaplumbağalarının yuvalaması ve popülasyonlarıyla ilgili ilk çalışmayı R. R. Hathaway ${ }^{8}$ yayınlamıştır. Sonra M. Başoğlư biri İzmir bölgesinde ve biri Köyceğiz' de olmak üzere iki adet $C$. caretta karapaksı tanımlanmış ve bu türün biyolojisi hakkında bilgi vermiştir. i̇. Baran ve M. Kasparek ${ }^{10}$ yuva yoğunluğunu temel alarak 17 önemli kumsal belirlemiştir. Bu sahillerden 13'ünü (Dalyan, Dalaman, Fethiye, Patara, Kumluca, Belek, Kızılot, Demirtaş, Kazanlı, Gazipaşa, Göksu Deltası, Akyatan ve Samandağ) "yüksek yoğunlukta yuvalama alanı", kalan 4 kumsalı ise (Ekincik, Kale, Tekirova ve Anamur) "düşük yoğunlukta yuvalama alanı" olarak belirlenmiştir. Daha sonraki çalışmalarla Olympos - Çıralı ${ }^{11}$, Akyatan ve Yumurtalık bu listeye eklenmiştir ${ }^{12}$. Sonraki çalışmalar Türkiye kumsallarında yuva yapan deniz kaplumbağası popülasyonlarının incelenmesi ve korunması üzerine devam etmiştir ${ }^{13}$. Türkiye'de deniz kaplumbağaları açısından önemli yuva-

1993; Canbolat 1997; Lutz - Musick 1997; Baran - Türkozan 1996; Türkozan - Baran 1996; Türkozan 2000;

Ilgaz - Baran 2001; Taşkın - Baran 2001.

4 Groombridge 1988; Yerli-Demirayak 1996.

5 IUCN 2015-1 listesine göre.

Dodd 1988; Groombridge 1988; Türkozan et al. 2003; Türkozan - Kaska 2010.

Canbolat 2004.

Hathaway 1972.

Başoğlu 1973.

10 Baran - Kasparek 1989.

11 Yerli-Demirayak 1996.

12 Yerli et al. 1998.

13 Canbolat 1991; Baran et al. 1992; Kaska 1993; Türkozan - Baran 1996; Türkozan 1998; 2000; Ilgaz - Baran 2001; Taşkın - Baran 2001; Erdoğan et al. 2001; Öz et al. 2004; Canbolat 2004; Ergene et al. 2007; Türkozan - Kaska 2010; Öz et al. 2011; Sevim 2014. 


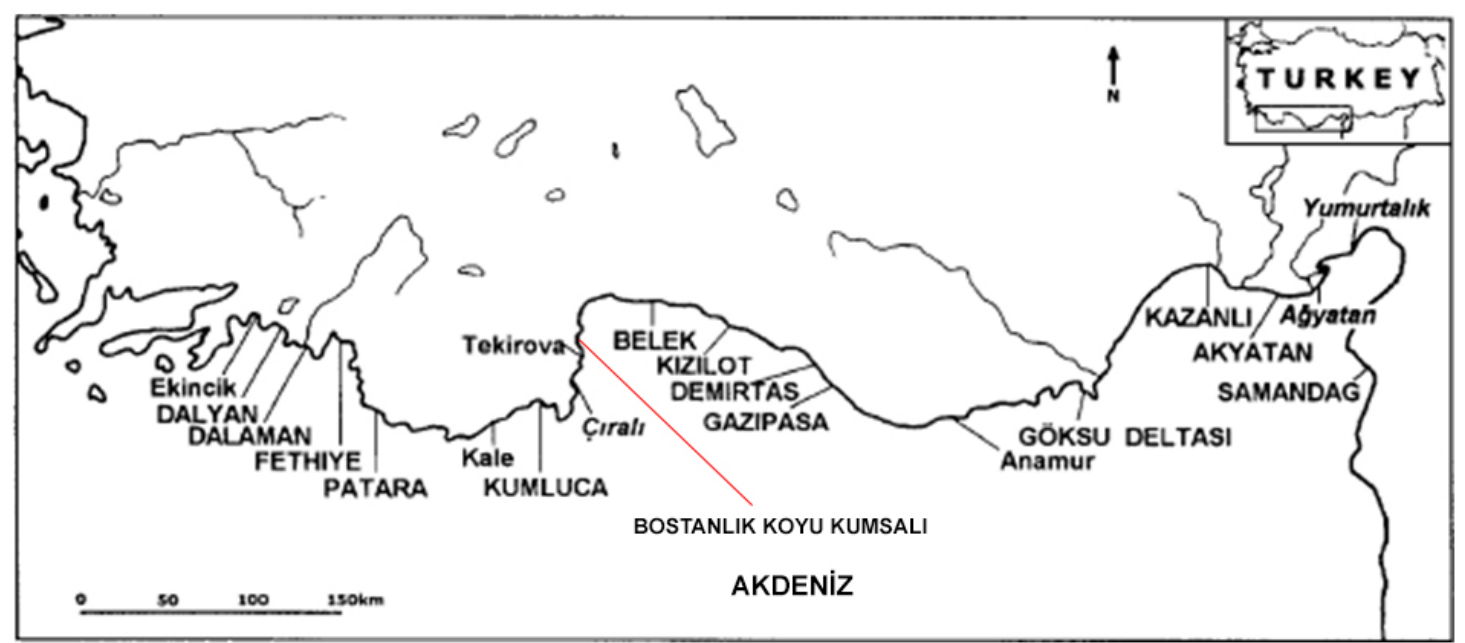

Fig. 1. Türkiye’nin Akdeniz Sahillerindeki Önemli Deniz Kaplumbağası Yuvalama Yerleri ve Bostanlık Koyu Kumsalı'nın Konumu ${ }^{14}$

lama alanı olan kumsallar aşağıdaki Fig.1'de verilmiştir.

Fig. 1'de de görüleceği üzere; bu araştırmanın konusu olan Bostanlık Koyu Kumsalı Tekirova'ya oldukça yakın mesafede yer almaktadır. Bu nedenle deniz kaplumbağaları açısından önemli sayılabilecek bir konumdadır.

Deniz kaplumbağaları açısından ülkemiz Akdeniz sahillerinin önemli bir rol oynamasından dolayı, bu alandaki bilimsel çalışmalar her geçen yıl artmaktadır. Ayrıca bu türlerin korunması ve araştırılmasına yönelik projeler devlet, sivil toplum kuruluşları ve basın tarafından da desteklenmektedir. Deniz kaplumbağalarıyla ilgili ülkemizde yapılan ilk yerli çalışma Et ve Balık Kurumu tarafından çıkarılan Balık ve Balıkçııı Dergisi'nde 1955 yılında yayımlanmıştır. Bu çalışmada ülkemiz sahillerinde büyük olasılıkla Caretta caretta ve Chelonia mydas bulunduğu belirtilmiştir ${ }^{15}$. C. caretta ve C. mydas türlerinin ülkemizde yuvaladıklarına dair ilk kaydı ise R. R. Hathaway 1972 yılında yapmıştır. O yıllardan günümüze kadar çok sayıda dar ya da geniş ölçekli çalışmalar ${ }^{16}$ yapılmış, deniz kaplumbağalarının ülkemiz sahillerindeki durumları aydınlatılmaya çalışımıştır.

Bu çalışma deniz kaplumbağası önemli yuvalama alanlarından biri olan Tekirova Kumsalı́nın yakınında ve doğusunda uzanan Bostanlık Koyu Kumsalı́nın 2015 yılı üreme döneminde deniz kaplumbağası popülasyonlarını inceleyen ilk detaylı çalışma olma niteliğindedir.

\section{Materyal ve Metot}

Bostanlık Koyu Kumsalı Tekirova'ya oldukça yakın mesafede yer almakta olup, kumsallar arası mesafe kuş uçuşu mesafe yaklaşık 1200 m civarındadır. Bostanlık Koyu Kumsalı ortasına yakın kısımdan uzanan kayalık burun nedeniyle Doğu (yaklaşık 350 m) ve Batı (yaklaşık 500 m) kumsalı

14 Türkozan et al. 2003'ten değiştirilerek.

15 Sözer 1955

16 Başoğlu 1973; Yntema - Mrosovsky 1980; Ackerman 1981; Başoğlu - Baran 1982; Geldiay - Koray 1982; Geldiay 1983; 1984; Dodd 1988; Groombridge 1988; Yerli 1990; Venizelos 1991; Baran et al. 1991; Canbolat 1991; Baran et al. 1992; Atatür 1992; Kaska 1993; 1998; Yerli - Demirayak 1996; Cheeks 1997; Durmuş 1998; Yerli - Canbolat 1998; Kaska et al. 1998; Wood - Bjorndal 2000; Türkozan 2000; Baran et al. 2001; Ilgaz - Baran 2001; Taşkın - Baran 2001; Kaska - Furness 2001; Erdoğan et al. 2001; Üzüm - Baran 2001; Türkozan - Durmuş 2001; Oruç et al. 2003; Hays et al. 2002; Türkozan et al. 2003; Canbolat 2004; Öz et al. 2011; Sevim 2014; Yavuz - Tunç 2015. 


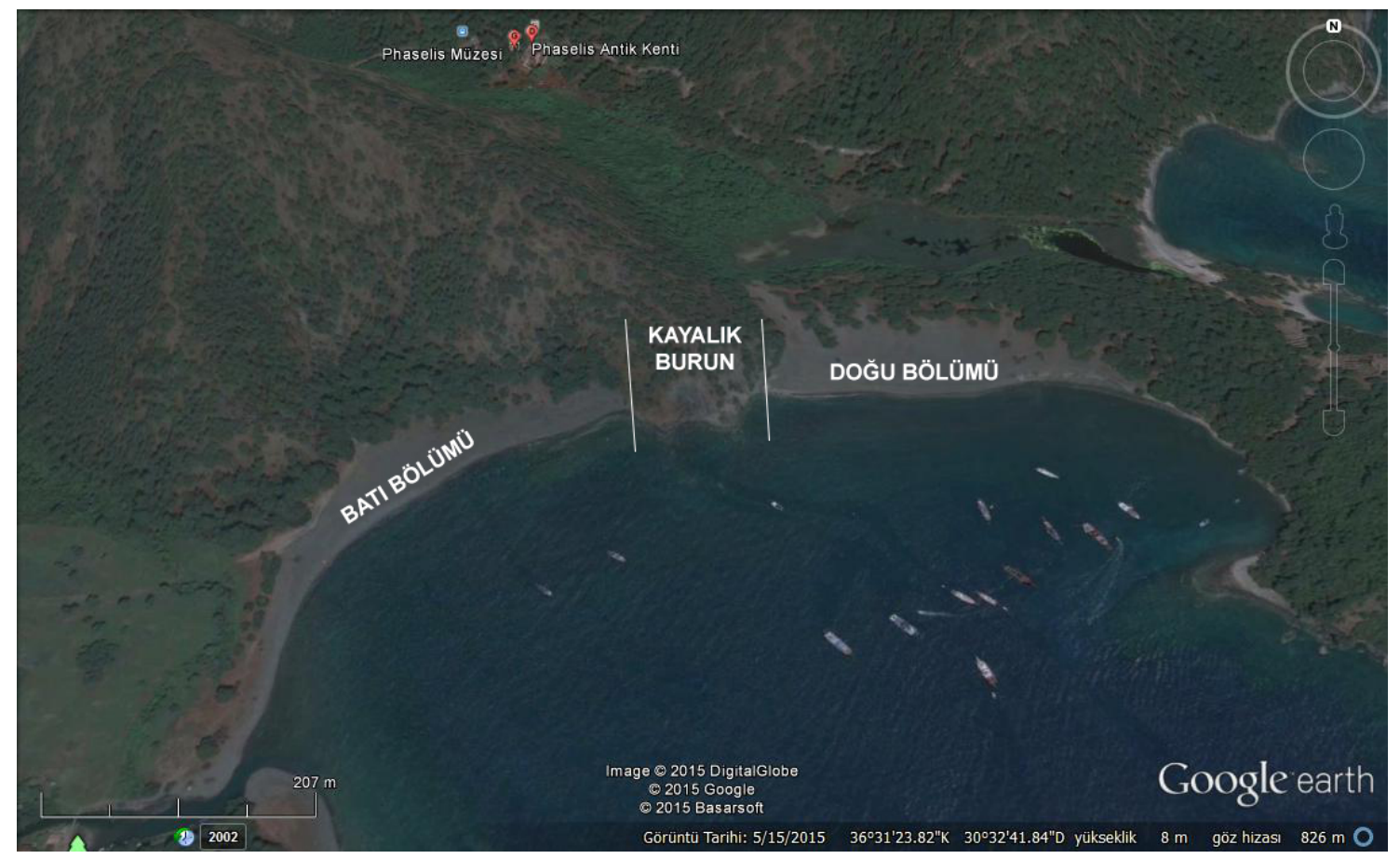

Fig. 2. Bostanlık Koyu Kumsalı’nın Uydu Görüntüsü ve Bölümleri

olarak iki ayrı bölüme ayrılmıştır (Fig. 2). Doğu bölümü yoğun turist kullanımı ve yerli halkın aktiviteleri nedeniyle ergin ve yavru çıkısına uygun gözükmemekle birlikte, nispeten çok daha sakin olan Batı bölümü ise ergin ve yavruların çıkışına uygun bir niteliktedir.

Çalışma kapsamında kumsalların durumunu incelemek ve değerlendirmek amacıyla Bostanlık Koyu Kumsalı'na 2015 yılı üreme sezonundan itibaren Mayıs ve Ekim ayları boyunca en az haftada bir kez olmak kaydıyla periyodik olarak gidilmiştir. Arazi çalışmaları sırasında kumsalın her iki bölümünde de iz çıkışı ve ergin birey çıkışları olup olmadığı incelenmiştir. Yumurta bırakmayla sonuçlanan ergin birey çıkışları "yuvalı çıkıs", yumurta bırakmadan yapılan çıkışlar ise "yuvasız çıkış" olarak adlandırılmıştır. M. Öz ve arkadaşlarının ${ }^{17}$ da belirttiği gibi yuvalı ve yuvasız ergin birey çıkışları, $21^{\frac{00}{-}}-24^{00}$ saatleri arasında gerçekleşebildiği gibi $24^{\frac{00}{}}-06^{00}$ saatleri arasında da gerçekleşebilmektedir. Bu zaman periyotları iki farklı güne ait olmasına karşın, olabilecek karışıklıkları önlemek için $21^{\underline{00}}-24^{00}$ saatleri arasında yapılan çıkışlar da bir sonraki gün yapıımış gibi değerlendirilmiştir. Predasyon ve yavru çıkış tarihlerinde de aynı şekilde değerlendirme yapılmıştır. Araştırmada ayrıca bu kumsala yuva yaptığı tespit edilen tek deniz kaplumbağası türü olan $C$. caretta türünün kumsalda bıraktıkları izlerin genişlikleri, kumsalın zonlarının enine uzunlukları (DIA: Daimi Islak Alan, YIA: Yarı Islak Alan ve KA: Kuru Alan) şerit metre ile ölçülerek tespit edilmiştir. Son olarak; her yuva için yavru çıkışlarının son gününü takip eden üç gün sonunda kontrol açıışı yapılarak, yuvada sıkışan ya da ölü yavru olup olmadığı kontrol edilmiştir

\section{Bulgular}

Sahada, ergin birey çıkışlarının ve yavru çıkışlarının gerçekleşeceği tahmin edilen 15 Mayıs ile 15 Ekim 2014 tarihleri arasında yapılan arazi ve ön çalışmada Bostanlık Koyu Kumsalı́nın Batı bölümünde toplam 12 adet yuva tespit edilmiş, bu yuvalardan 8'inde (\%66.7) yavru çıkışı gerçek-

17 Öz et al. 2011. 
leşmiştir. Geri kalan 4 yuva ise predatörler tarafından tahrip edilmiştir. Kumsalda ayrıca 10 adet yuvasız çıkış tespit edilmiştir. Diğer taraftan turistlerin ve halkın yoğun olarak kullandığı Doğu bölümünde ise hiçbir çıkışa rastlanmamıştır. Önceki yılda yuva yapımının gerçekleşmediği (yoğun insan aktivitesi ve kullanımı nedeniyle olabilir) Doğu bölümünün genel görünümü Fig. 3'te verilmiştir. Nispeten daha sakin olan ve insan aktivitesinin çok olmadığı Batı bölümünde yapılan yuvalardan bazıları ve koordinatları ise Fig. 4-5'te verilmiştir.

Kumsalın Batı bölümü her ne kadar sakin olsa da, bu kısımda yoğun bir predasyon bas-

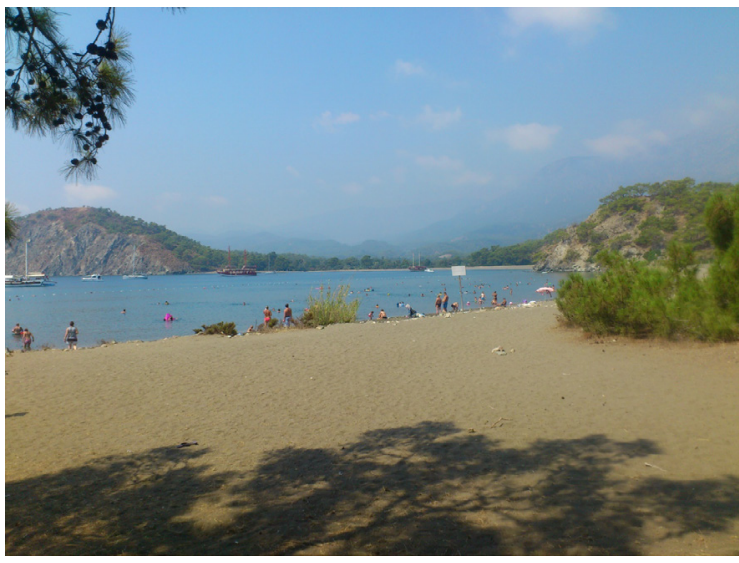

Fig. 3. Caretta caretta'nın Yuva Yapmayı Tercih Etmediği Doğu Bölümü ve Sahildeki Yoğun insan Aktivitesi kısı olduğu gözlenmektedir. Özellikle, sansar, tilki ve köpek gibi predatörlerin yuvaları daha kuluçka aşamasındayken tespit edip, sıklıkla buralarda dolaştıkları, erişebildikleri yuvaları kazdıkları görülmüştür. Predatörler tarafından tahrip edilmiş yuvalara bazı örnekler, bazı predatörlerin izleri Fig. 6-8'de, kontrol amaçlı kazılan bir yuva ise Fig.9'da verilmiştir.

Yoğun predatör baskısına rağmen yavru çıkışının gerçekleşebildiği yuvalardan (8 yuva) $15 \mathrm{Ha}$ ziran 2015 tarihi itibariyle ilk yavrular çıkmaya başlamıştır. Son yavru çıkışı ise 28 Eylül'de gerçekleşmiştir. Her yuva için yavru çıkışlarının son gününü takip eden üç gün sonunda kontrol açılışı yapılarak, yuvada sıkışan ya da ölü yavru olup olmadığı kontrol edilmiştir (Fig. 9). Bu kontrollerde herhangi bir ölü yavruya rastlanılmamıştır.

Genel bir değerlendirme ile; kumsala çıkan ergin bireylerin iz genişlikleri 75-80 cm arasında olup, DIA (Daimi Islak Alan) uzunluğu; 4-10 m arasında, YIA (Yarı Islak Alan) uzunluğu; 5-10 m. arasında ve KA (Kuru Alan) uzunluğu ise $5-20 \mathrm{~m}$ arasında değişmektedir. YIA veya DIA kısımlarına yapılmış herhangi bir yuvaya rastlanılmamıştır.

Bunun yanında kumsalın özellikle gündüz saatlerinde insan kullanımına açık olması ve de yoğun insan-araç trafiği nedeniyle neredeyse sürekli bir kalabalık söz konusudur (özellikle Doğu bölümünde). Bu durumda önceki yıllarda olduğu gibi; gündüz insanlar gece kaplumbağalar tarafından kullanılan kumsalda insanın istekleriyle, kaplumbağaların yaşam döngüsü nedeniyle yapmaya mecbur oldukları faaliyetler çakışmaktadır. Bir önceki yıl 2014 üreme sezonunda da olduğu gibi çoğu zaman kumsalda araç izlerine bile rastlanmaktadır (Fig. 10-11). Yine yoğun insan kullanımı ve umursamazlık nedeniyle kumsalda bırakılan çöpler görüntü kirliliği ve çevre kirliliği oluşturmanın da ötesinde kaplumbağalar için de tehlike oluşturmaktadır (Fig. 12). Özellikle poşetlerin ve pet şişelerin denizde yumuşakçalara benzeyen görünümleri nedeniyle deniz kaplumbağaları tarafından besin zannedilerek tüketildikleri, bunun neticesinde ise ölümle sonuçlanabilecek olaylarla karşılaşıldığı bilinmektedir.

Tüm bunların üzerine, kumsal ve kıyı boyunca balık avcılığının yasak olmasına rağmen amatör balıkçıların ağ ve misinalarını kıyıda bırakmaları özellikle ergin bireyler açısından çok büyük tehlike oluşturmaktadır (Fig. 13-14). Misina ve ağ gibi malzemelerin üye ve vücutlarına dolanması nedeniyle kaplumbağalar yaralanabilmekte ve hatta ölmektedirler. 


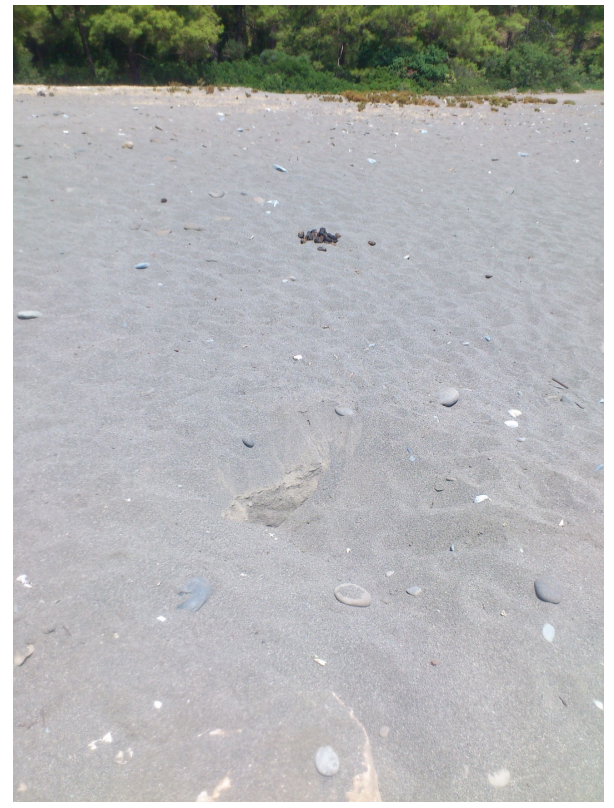

Fig. 4. Doğu Bölümünde Tespit Edilen Bir Yuva

(Koordinat: K: 36.31.21, 97 D:30.32.30, 71)

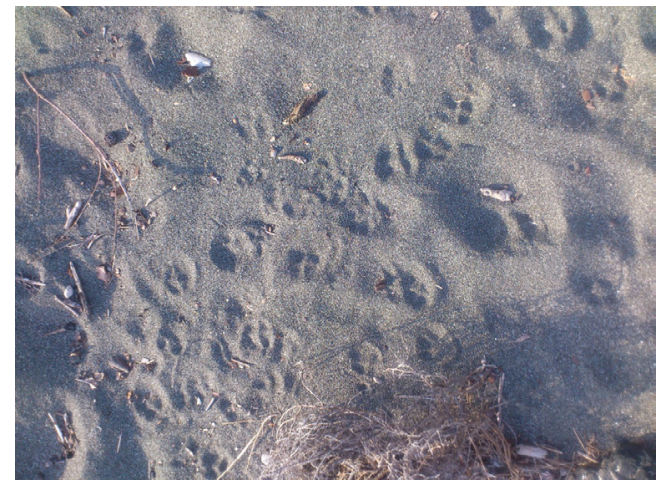

Fig. 6. Yuva Yakınında Dolaşan Bir Predatörün (Muhtemelen Köpek) Ayak İzleri

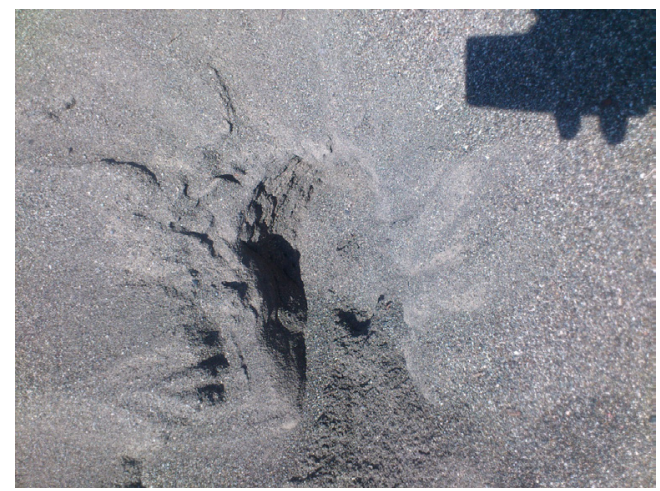

Fig. 8. Predatör Tarafından Kazılmış Bir Yuva (Koordinat: K: 36.31.22, 76 D:30.32.31, 51)

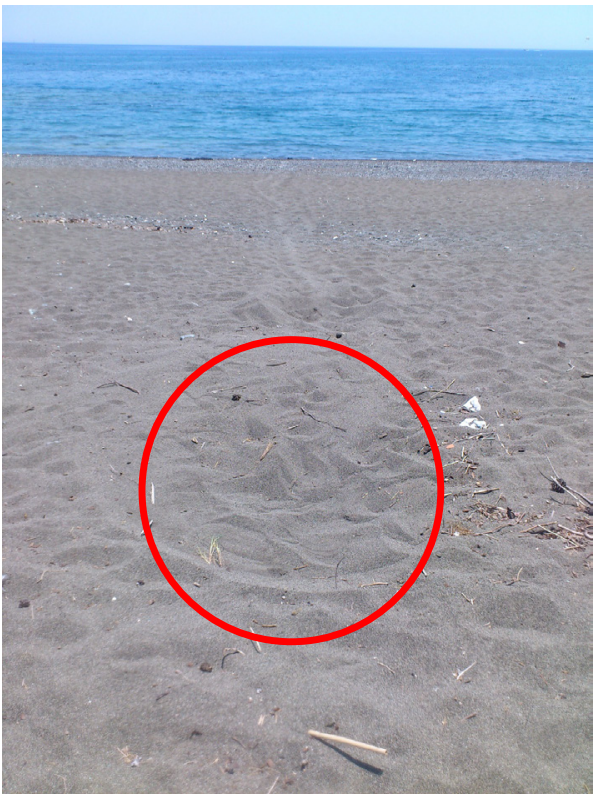

Fig. 5. Kumsalın Doğu Bölümünde Tespit Edilen Bir Diğer Yuva (Koordinat: K: 36.31.22, 41 D:30.32.31, 60)

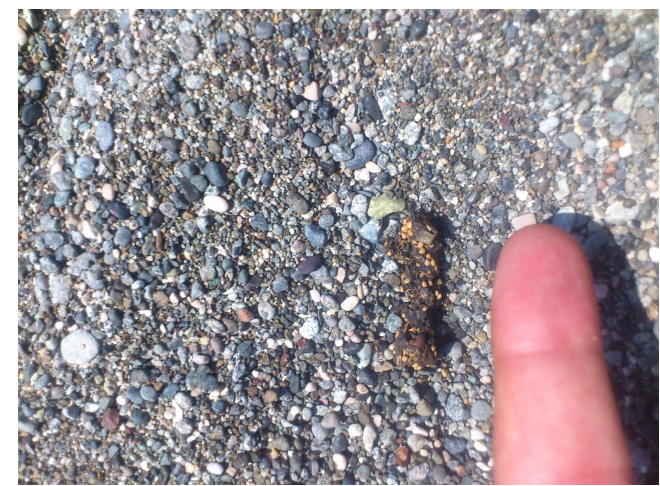

Fig. 7. Yuva Yakınında Gezinmiş Bir Predatörün (Muhtemelen Sansar) Dışkısı

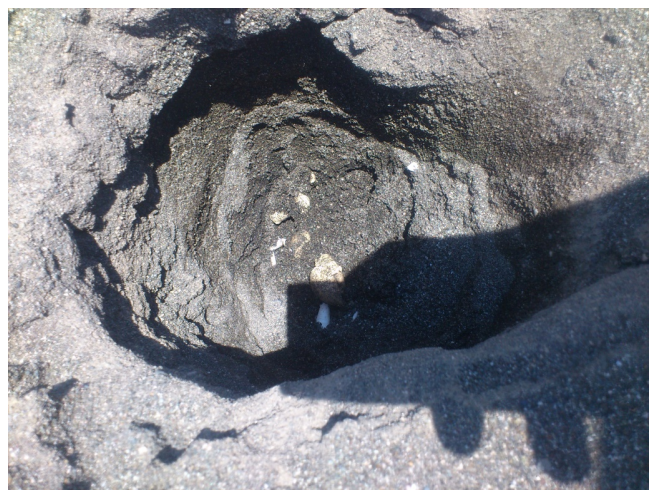

Fig. 9. Yavru Çıkışlarının Bitişini Takip Eden Süreden Üç Gün Sonra Kontrol Açıșı Amacıyla Açılan Bir Yuva (Koordinat: K: 36.31.19, 36 $D: 30.32 .28,47)$ 


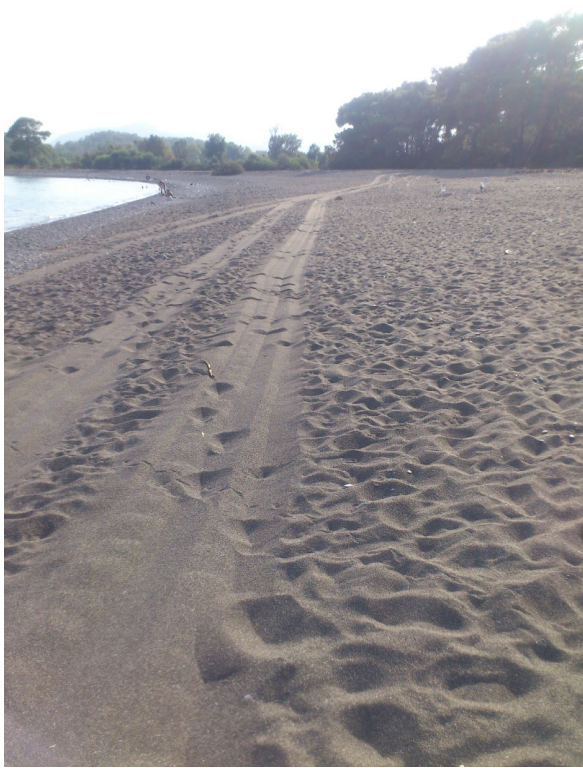

Fig. 10. Kumsalın Yoğun Yuvalama Alanı Olan Batı Bölümünde Kumsaldaki Kıyıya Paralel Araç Izleri

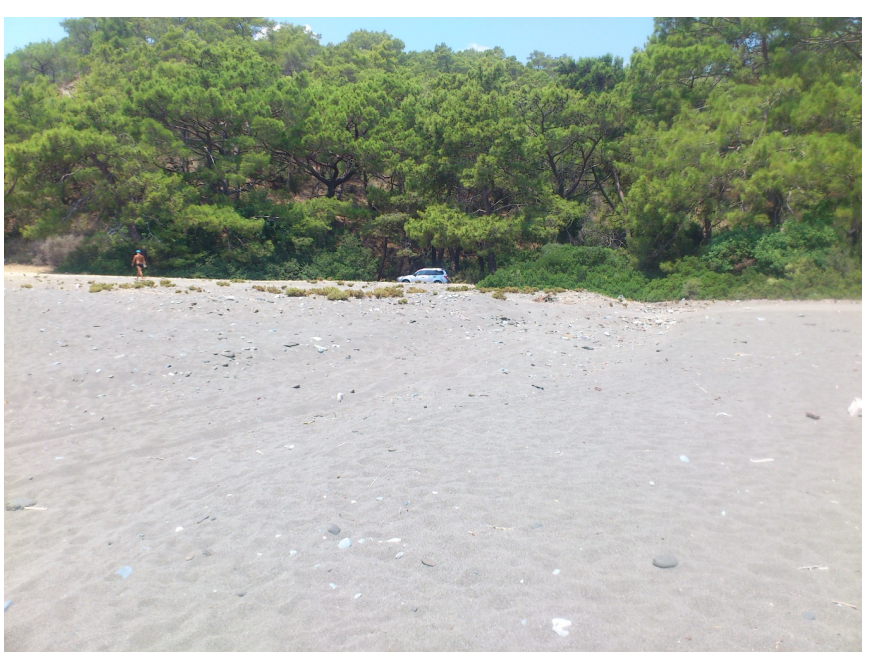

Fig. 11. Yine Batı Bölümünde Kıyıya Kadar Inip Geri Gelen Arazi Aracı ve İzleri

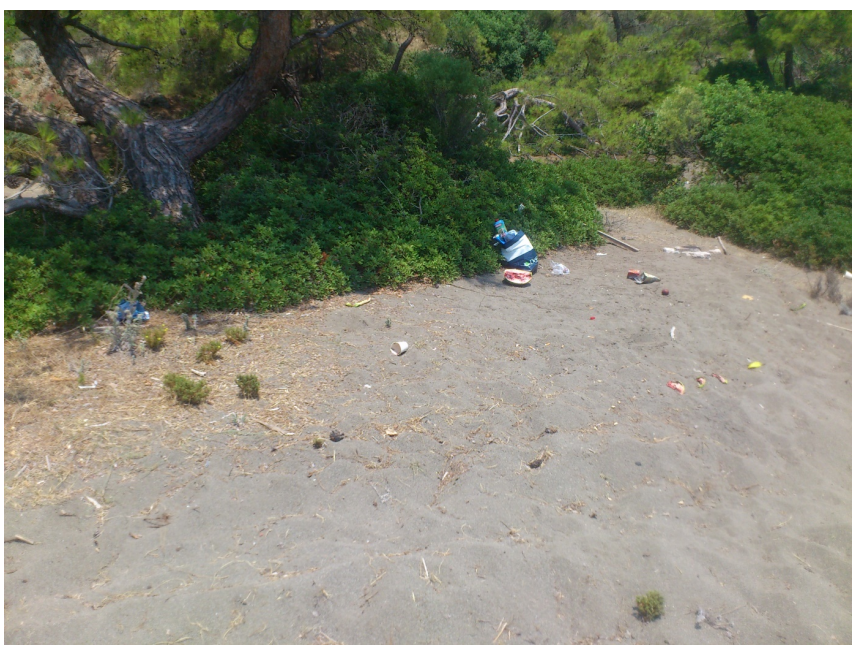

Fig. 12. Batı Bölümünde Kumsalda Bırakılan Çöpler, Pet Şişe ve Poşetler

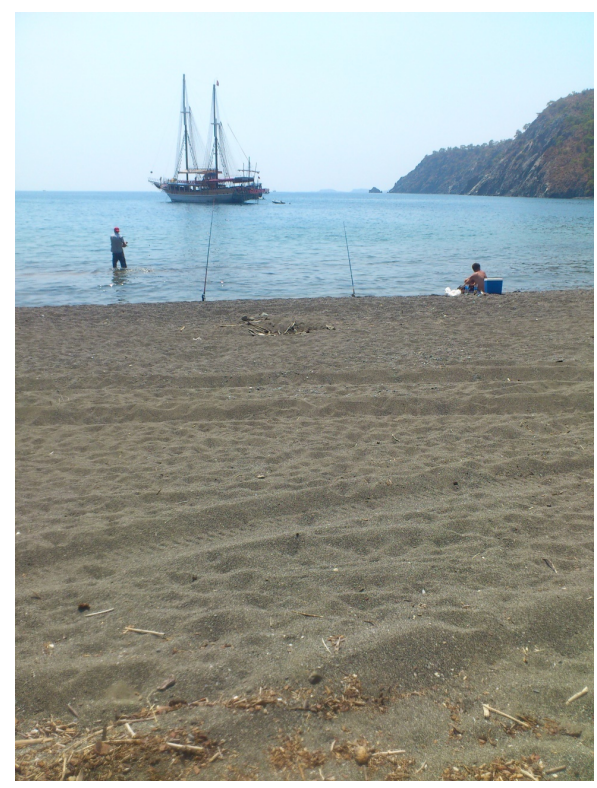

Fig. 13. Batı Bölümünde Kumsalda Balık Tutan Amatör Balıkçılar 


\section{Sonuç}

Bu çalışma döneminde 2014 yılında M. Yavuz ve M. R. Tunç tarafından Phaselis antik kenti bünyesindeki Bostanlık Koyu Kumsalı'nda varlığı tespit edilen $C$. caretta türünün popülasyonu izlenmiştir. Bu bakımdan 2014 yılında üreme sezonunda yapılan ön çalışmadan sonra yapılan bu çalışma daha detaylı olması bakımında önemlidir. Ancak gerek kumsalın durumunun, gerekse deniz kaplumbağası populasyonunun özelliklerinin ortaya konulabilmesi için çok daha detaylı bir çalışmaya ihtiyaç vardır. Bu nedenle 2016 yılı için Mayıs-Ekim ayları arasında (üreme sezonuna uygun olarak) geniş çaplı bir çalışma yapılarak (bir yüksek lisans tezi kapsamında) popülasyonun durumunun, kumsal sıcaklık profillerinin ve ekolojik özelliklerin değerlendirilmesi düşünülmektedir. Tüm bu bilgiler ve veriler ışığında önümüzdeki yıllarda yapılacak çalışmalarla Bostanlık Koyu Kumsalı'nda yuva yapan popülasyonla ilgili çok daha geniş ve sağ|ıklı verilere ulaşılması hedeflenmektedir.

Hali hazırda doğal yapısı hızla bozulan kumsallarımız dikkate alındığında, Bostanlık Koyu Kumsalı kısmen korunmuş durumdadır. Ancak yoğun insan aktivitesi ve faaliyetleri kumsalı ve kumsala bağlı popülasyonları tehdit eder duruma gelmiştir. Sadece ulusal değil, uluslararası ölçekte aktüel ve dikkat çekici bir tür olan C. caretta'nın kumsallarımızdaki varlığı temiz deniz indikatörü türler olarak kabul edilmeleri nedeniyle ayrıca önemlidir. Bilinçli turistin bu tip temiz deniz indikatörü türlerin olduğu kumsalları tercih ettikleri bilinmektedir. Bu bakımdan bu tip kumsallarımızın koruma altına alınması şarttır. Gerekli önlemler alınarak, gündüz ve gece kullanım planlamaları ve tür eylem planları oluşturularak ekolojik bir turizmin gerçekleştirilmesi çok daha verimlidir ve zor değildir. Gelecek yıllarda yapılacak geniş ölçekli çalışmalar Bostanlık Koyu Kumsalı'nın aktif bir yuvalama kumsalı olduğunu teyit etmeye devam ederse, kumsalın korunması için ilgili makamlara başvuru yapılması kaçınılmaz bir gerekliliktir. 


\section{BIBLIYYGRAFYA}

Ackerman 1981

Atatür 1992

Baran 1990

Baran et al. 1991

Baran et al. 1992

Baran et al. 2001

Baran - Kasparek 1989

Baran - Türkozan 1996

Başoğlu - Baran 1982

Başoğlu 1973

Canbolat 1991

Canbolat 1997

Canbolat 2004

Cheeks 1997

Dodd 1988

Durmuş 1998

Erdogan et al. 2001

Ergene et al. 2007

Geldiay 1983

Geldiay 1984
R. A. Ackerman, "Growth and Gas Exchange of Embriyonic Sea Turtles (Chelonia, Caretta)". Copeia 4 (1981) 757-765.

K. M. Atatür, Türkiye Deniz Kaplumbağaları Biyolojileri ve Korunmaları. Bodrum 1992.

i. Baran, "Sea Turtles in Turkey". Marine Turtle Newsletter 48 (1990) 21-22.

i. Baran, M. K. Atatür - S. H. Durmuş, "On Chelonia mydas (L.) (Reptilia: Chelonia) Population of Mersin-Kazanlı Region". Doğa Türk Zooloji Dergisi 15 (1991) 185-194.

i. Baran, S. H. Durmuş, E. Çevik, S. Üçüncü - A. F. Canbolat, "Türkiye Deniz Kaplumbağaları Stok Tespiti”. Doğa Türk Zooloji Dergisi 16 (1992) 119-139.

i. Baran, A. Özdemir, Ç. Ilgaz - O. Türkozan, "Impact of Some Invertebrates on Eggs and Hatchlings of the Loggerhead Turtle, Caretta caretta, in Turkey". Zoology in the Middle East 24 (2001) 9-17.

i. Baran - M. Kasparek, Marine Turtles in Turkey. Status Survey 1988 and Recommendation for Conservation and Management. Hiedelberg 1989.

i. Baran - O. Türkozan, "Nesting activity of the loggerhead turtle, Caretta caretta, on Fethiye Beach, Turkey, in 1994". Chelonian Conservation and Biology 2/1 (1996) 93-96.

M. Başoğlu - İ. Baran, "Anadolu Sahillerinden Toplanan Deniz Kaplumbağası Materyali Üzerinde Kısa Bir Rapor". Doğa Bilim Dergisi 6/2 (1982) 69-71.

M. Başoğlu, "Sea Turtles and the Species Found Along the Coast of Neighboring Countries". Türk Biyoloji Dergisi 23 (1973) 12-21.

A. F. Canbolat, "Dalyan Kumsalı (Muğla, Türkiye)'ında Caretta caretta (Linnaeus, 1758) Populasyonu Üzerine İncelemeler". Doğa Türk Zooloji Dergisi 15 (1991) 255-274.

A. F. Canbolat, Dalyan ve Patara Caretta caretta (Linnaeus, 1758) Deniz Kaplumbağası Populasyonlarının Biyolojisi. Yayımlanmamış Doktora Tezi, Hacettepe Üniversitesi. Ankara 1997.

A. F. Canbolat, "A Review of Sea Turtle Nesting Activity Along the Mediterranean Coast of Turkey". Biological Conservation 116 (2004) 81-91.

R. J. Cheeks, Effects of Various Sand Types on Nest Temperature and Hatching Success in the Loggerhead (Caretta caretta) Sea Turtle. Master of Science Thesis, Florida Atlantic University. Florida 1997.

Jr. C. K. Dodd, "Synopsis of the Biological Data on the Loggerhead turtle Caretta caretta (Linnaeus 1758)". U. S. Fish and Wildlife Service Biological Report 88 (1988) 1-110.

S. H. Durmuş, An Investigation on Biology and Ecology of the Sea Turtles Population on Kazanlı and Samandağ Beaches. Yayımlanmamış Doktora Tezi, Dokuz Eylül Üniversitesi. İzmir 1998.

A. Erdogan, M. Öz, Y. Kaska, A. Düşen, A. Aslan, M. Yavuz, M. R. Tunç -H. Sert, "Marine Turtle Nesting at Patara, Turkey, in 2000". Zoology in the Middle East 24 (2001) 31-34.

S. Ergene, A. H. Uçar - C. Aymak, "Demre (Kale) Kumsalı'nda Yuva Yapan Caretta caretta Populasyonunun Araştırılması". Ege Üniversitesi Su Ürünleri Dergisi 24 (2007)239-246.

R. Geldiay, "Deniz Kaplumbağalarının (Caretta c.careta, ve Chelonia mydas L.) Populasyonları ve Korunmasında Temel Bilimler Yönünden Takip Edilecek Stratejinin Önemi”. Ege Üniversitesi Fen Fakültesi Dergisi 1 (1983) 328-349.

R. Geldiay, "Türkiye'nin Ege ve Akdeniz Kıyılarında Yaşayan Deniz Kaplum- 
Geldiay - Koray 1982

Groombridge 1988

Groombridge 1990

Hathaway 1972

Hays et al. 2002

Ilgaz - Baran 2001

IUCN 2015

Kaska 1993

Kaska 1998

Kaska et al. 1998

Kaska - Furness 2001

Lutz - Musick 1997

Mrosovsky 1983

Mrosovsky 1994

Oruç et al. 2003

Öz et al. 2004

Öz et al. 2011

Sella 1982 bağalarının (Caretta caretta ve Chelonia mydas) Populasyonları ve Korunması ile İlgili Araştırmalar". Doğa Bilim Dergisi 8 (1984) 66-75.

R. Geldiay - T. Koray, “Türkiye'nin Ege ve Akdeniz Kıyılarında Yaşayan Deniz Kaplumbağalarının (Caretta caretta ve Chelonia mydas) Populasyonları ve Korunmaları ile Illgili Tedbirler Üzerine Araştırmalar". TÜBiTAK (1982) 1-121. B. Groombridge, Marine Turtles in the Mediterranean: Distribution, Population Status, Conservation, World Conservation Monitoring Centre. Cambridge 1988.

B. Groombridge, Marine Turtles in the Mediterranean; Distribution, Population Status, Conservation: A Report to the Council of Europe, World Conservation Monitoring Centre. Cambridge 1990.

R. R. Hathaway, "Sea turtle, Unanswered Questions about Sea Turtles in Turkey". Balık ve Balıkçılık 20/1 (1972) 1-8.

G. C. Hays, A. C. Broderick, F. Glen, B. J. Godley, J. D. R. Houghton - J. D. Metcalfe, "Behavioural Plasticity in a Large Marine Herbivore: Contrasting Patterns of Depth Utilisation between Two Green Turtle (Chelonia mydas) Populations". Marine Biology 141 (2002) 985-990.

Ç. Ilgaz - I. Baran. "Reproduction Biology of the Marine Turtle Populations in Northern Karpaz (Northern Cyprus) and Dalyan (Turkey)". Zoology in the Middle East, 24 (2001) 35-44.

IUCN - Red List of Threatened Species. Version 2015. 3.

Kaynak: www.iucnredlist.org.

Y. Kaska, Investigation of Caretta caretta in Patara and Kızılot. Unpublished Master Thesis, Dokuz Eylül University. İzmir 1993.

Y. Kaska, Studies on the Embryology, Ecology and Evolution of Sea Turtles in the Eastern Mediterranean. Unpublished Doctoral Dissertation, Glasgow University. Glasgow 1998.

Y. Kaska, R. Downie, R. Tippet - R. W. Furness, "Natural Temparature Regimes for Loggerhead and Green Turtle Nests in the Eastern Mediterranean". Can. J. Zool. 76 (1998) 723-729.

Y. Kaska - W. R. Furness, "Heavy Metals in Marine Turtles Eggs and Hatchlings in the Mediterranean". Zoology in the Middle East 24 (2001) 127-132.

P. L. Lutz - J. M. Musick, The Biology of Sea Turtles. New York 1997.

N. Mrosovsky, Conserving Sea Turtles. London 1983.

N. Mrosovsky, "Sex Ratios of Sea Turtles". Journal of Experimental Zoology 270 (1994) 16-27.

A. Oruç, T. Ozan - S. H. Durmuş, Deniz Kaplumbağalarının Izinde, Doğal Hayatı Koruma Derneği - Deniz Kaplumbağası Yuvalama Kumsalları Değerlendirme Raporu. İstanbul 2003.

M. Öz, A. Erdoğan, Y. Kaska, S. Düşen, A. Aslan, H. Sert, M. Yavuz - M. R. Tunç, "Nest Temperatures and Sex-Ratio Estimates of Loggerhead Turtles at Patara Beach on the Southwestern Coast of Turkey". Canadian Journal of Zoology 82 (2004) 94-101.

M. Öz, A. Erdoğan, M. Yavuz, H. Karaardıç - L. Özkan, Belek Özel Çevre Koruma Bölgesi Kumsal Alanında Deniz Kaplumbağaları (Caretta caretta, Chelonia mydas) ve Nil Kaplumbağası (Trionyx triunguis) PopulasyonIarının İlenmesi ve Korunması Projesi, Teknik Rapor. Antalya 2011.

I. Sella, "Sea Turtles in the Eastern Mediterranean and Northern Red Sea". Ed. K. A. Bjorndal, Biology and Conservation of Sea Turtles. Washington (1982) 417-423. 
Sevim 2014

Sözer 1955

Taşkın - Baran 2001

Türkozan 1998

Türkozan 2000

Türkozan - Baran 1996

Türkozan - Durmuş 2001

Türkozan et al. 2003

Türkozan - Kaska 2010

Üzüm - Baran 2001

Venizelos 1991

Wood - Bjorndal 2000

Yavuz - Tunç 2015

Yerli 1990

Yerli et al. 1998

Yerli - Canbolat 1998

Yerli-Demirayak 1996

Yntema - Mrosovsky 1980
R. Sevim, Sülüklü Kumsalı (Demre-Antalya)'ndaki Caretta caretta (Lineaus, 1758) (Chelonia: Cheloniidae) Populasyonlarının Izlenmesi ve Yavruların Eşey Oranlarının Belirlenmesi. Yayımlanmamış Yüksek Lisans Tezi, Akdeniz Üniversitesi. Antalya 2014.

H. Sözer, "Türkiye'de Deniz Kaplumbağaları ile İlgili Cevaplandırılmamış Sorular". Balık ve Balıkçılık 3 (1955) 4-5.

N. Taşkın - I. Baran, "Reproductive Ecology of the Loggerhead Turtle, Caretta caretta, at Patara, Turkey". Zoology in the Middle East 24 (2001) 91-100.

O. Türkozan, Investigation on the Marine Turtle Population of Fethiye and Kızılot Beaches. Yayımlanmamış Doktora Tezi, Dokuz Eylül Üniversitesi. İzmir 1998.

O. Türkozan, "Reproductive Ecology of the Loggerhead Turtle, Caretta caretta, on Fethiye and Kızılot Beaches, Turkey". Chelonian Cons. and Bio/ 3/4 (2000) 686-692.

O. Türkozan - I. Baran, "Research on the Loggerhead Turtle, Caretta caretta, of Fethiye Beach". Doğa Türk Zooloji Dergisi 20 (1996) 183-188.

O. Türkozan - S. H. Durmuş, "Albino Loggerhead and Green Turtle Hatchlinsgs (Caretta caretta and Chelonia mydas) in Turkey". Zoology in the Middle East 24 (2001) 133-136.

O. Türkozan, Ç. Ilgaz, E. Taşkavak - A. Özdemir, "Hatch Rates of Loggerhead Turtles and Physical Characteristics of the Beach at Fethiye, Turkey". Journal of the Marine Biological Association of the United Kingdom 83 (2003) 231232.

O. Türkozan - Y. Kaska, "Sea Turtles in the Mediterranean: Distribution, Threats and Conservation Priorities". Eds. P. Casale - D. Margaritoulis, Turkey. Gland (2010) 257-293.

N. Üzüm - İ. Baran, "Reproductive Ecology of the Loggerhead Turtle, Caretta caretta at Patara, Turkey". Zoology in the Middle East 24 (2001) 91-100.

L. E. Venizelos, "Pressure on the Endangered Mediterranean Marine Turtles is Increasing. The Role of Medasset". Marine Pollution Bulletin 23 (1991) 613-616.

D. W. Wood-K. A. Bjorndal, "Relation of Temperature, Moisture, Salinity, and Slope to Nest Site Selection in Loggerhead Sea Turtles". Copeia 1 (2000) 119-128.

M. Yavuz - M. R. Tunç, "Bostanlık Koyu Kumsalı'nda (Phaselis/Antalya) Caretta caretta (Linnaeus, 1758) Populasyonları Hakkında Ilk Bulgular". Phaselis I (2015) 291-302.

S. V. Yerli, “Patara Kumsalı (Antalya)'na Yuva Yapan Deniz Kaplumbağaları (Caretta caretta Linnaeus) Üzerine İncelemeler". Hacettepe Fen ve Mühendislik Bilimleri Dergisi 11 (1990) 133-143.

S. Yerli, A. F. Canbolat, H. Uluğ - O. Doğan, Principles of the Management Plan for the Protection of Sea Turtles in the West Mediterranean Cosats of Turkey (in Turkish). Ankara 1998.

S. V. Yerli - A. F. Canbolat, "Results of a 1996 Survey of Chelonia in Turkey". MTN 79 (1998) 9-11.

S. Yerli - F. Demirayak, Marine Turtles in Turkey: A Survey on Nesting Site Status (in Turkish). İstanbul 1996.

C. L. Yntema - N. Mrosovsky, "Sexual Differentiation in Hatchling Loggerheads (Caretta caretta) Incubated at Different Controlled Temperatures". Herpetologica 36 (1980) 33-36. 